Brotto, D.S.; Pedrini, A.G.; Bandeira, R.R.C.; Zee, D.M.W. Percepção ambiental do mergulhador recreativo no Município do Rio de Janeiro e adjacências: subsídios para a sustentabilidade do ecoturismo marinho. Revista Brasileira de Ecoturismo, São Paulo, v.5, n.2, mai/ago2012, pp.297-314.

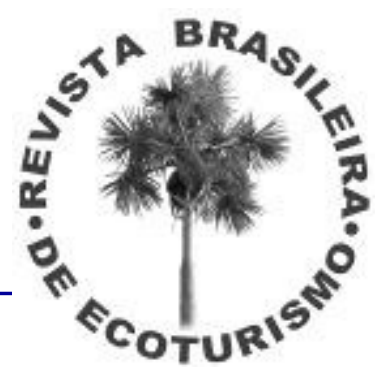

\title{
Percepção ambiental do mergulhador recreativo no Município do Rio de Janeiro e adjacências: subsídios para a sustentabilidade do ecoturismo marinho
}

\author{
Environmental perception of recreational divers in Rio de Janeiro city and \\ surrounding areas: subsides aiming the sustainability of marine ecotourism
}

\section{Daniel Shimada Brotto, Alexandre de Gusmão Pedrini, Raquel Ribeiro Cezar Bandeira, David Man Wai Zee}

\begin{abstract}
RESUMO
O mergulho recreativo marinho é uma das atividades mais desenvolvidas dentre as exploradas na zona costeira do município do Rio de Janeiro. O estudo caracterizou e avaliou preliminarmente a percepção ambiental de mergulhadores recreativos e os possíveis impactos negativos que essa prática pode causar na zona costeira do município e adjacências. Foram elaborados questionários específicos para a coleta de dados primários junto a merguIhadores recreativos e gestores de operadoras e escolas de mergulho. A amostragem consistiu em 35 questionários respondidos por mergulhadores recreativos e sete por gestores de escolas e operadoras do mesmo município. Os dados foram digitalizados em planilhas eletrônicas para sua analise estatística pelo Programa Statistica. Os mergulhadores recreativos analisados são na maioria adultos de 20-40 anos, com escolaridade de nível superior e distribuída de forma equilibrada entre homens e mulheres, com variados padrões de renda familiar. Os gastos com saídas e equipamentos variaram significativamente (Qui-quadrado, $p<0,1 \%$ ) de acordo com a renda familiar e faixa etária. Os mergulhadores com menos qualificações em cursos de mergulho são os que mais tocam e revolvem o fundo. Os impactos ambientais negativos da atividade do mergulho são: a) interação com a biota; b) presença de lixo. A maioria dos mergulhadores apontou que a disposição adequada de lixo, evitar o óleo na água e ancoragem adequada são soluções para minimizar o impacto negativo dos mergulhos recreativos. Todos foram unânimes de que não se deve tocar o fundo. Os subsídios técnicos propostos são: 1) a necessidade urgente da inclusão de conteúdos sobre os ecossistemas aquáticos nos cursos do nível básico à dive-master, na forma de materiais impressos e preleções; 2) Especial atenção dos guias e instrutores aos iniciantes e mergulhadores com qualificação básica; 3 ) devem-se evitar ecossistemas sensíveis para instrução de novos alunos, batismos subaquáticos e visitação por mergulhadores básicos; 4) o uso correto do colete hidrostático deve ser obrigatório; 5) treinamentos para o correto deslocamento submerso devem ser inseridos nos cursos; 6) preleções abrangentes devem ser feitas previamente à qualquer mergulho realizado por um grupo de alunos ou turistas; 7) as certificadoras devem realizar o acompanhamento e avaliação constante do trabalho dos guias e instrutores. A adoção dessas simples medidas pelos profissionais do setor do mergulho recreativo trará inúmeros benefícios para o setor e a integridade dos ecossistemas visitados, possibilitando um ecoturismo marinho sustentável.
\end{abstract}

PALAVRAS-CHAVE: Zona Costeira; Turismo de Mergulho Marinho, Sustentabilidade Ambiental. 
Percepção ambiental do mergulhador recreativo no Município do Rio de Janeiro e adjacências: subsídios para a sustentabilidade do ecoturismo marinho

\begin{abstract}
Marine recreational diving stands out among one of the most profitable services in the coastal area of Rio de Janeiro. The paper describes and evaluates the environmental perception of recreational divers and the possible impacts that may be caused by this activity in Rio de Janeiro coastal zone and surroundings. Specific questionnaires were elaborated for primary data collection from recreational divers and managers of diving shops and schools. The whole sample comprised by 35 questionnaires filled by recreational divers resident in Rio de Janeiro city and 7 by managers of diving shops and schools situated at the same city. All collected data was statistically analyzed in electronic spreadsheets by Statistica Program. The majority of divers surveyed were adults between 20 to 40 years old, with graduated degree and evenly distributed among men and woman. They presented different patterns of income and their expenditures with diving trips and equipments varied significantly (Chi-square, $p<0,1 \%$ ) according to their incomes and age. The divers with less qualification (diving courses) were the ones who touch the substrate and also revolve the sediment more frequently. The negative environmental impacts due the diving activity are the following: a) the interaction with marine life; b) littering. Most of the divers point out that adequate litter disposal, avoidance of oil pollution and correct anchoring are solutions for minimizing the negative impact due the recreational diving. All divers are unanimous that it was not allowed to touch bottom. This research brought some important technical subsides, listed as following: 1) it is urgent that some knowledge related to the aquatic environment were added to the contends of diving courses from basic to dive-master levels as printed materials or teachings; 2) especial attention must be given by diving guides and instructors to beginners and basic qualification divers; 3) sensitive ecosystems must be avoided for field classes, diving baptism and visitation by basic level divers, 4) the correct use of buoyancy equilibrator must be obligatory; 5) training for correct underwater movements and swimming must be included among diving courses teachings; 6) comprehensive teachings must be performed previously and along each dive by a group of tourists or at field classes; 7) recreational diving associations must perform comprehensive follow ups and evaluation of the personal employed at their affiliated diving shops and schools. It is believed that the throughout adoption of these simple procedures by the professionals involved in the recreational diving, will be possible to obtain innumerous benefits to that activity as well as the integrity of these visited ecosystems.
\end{abstract}

KEYWORDS: Coastal Zone; Marine Diving Tourism; Environmental Sustainability.

\title{
Introdução
}

No Brasil, devido a diversidade e exuberância dos seus ecossistemas marinhos e costeiros, o ecoturismo, o turismo de aventura e o de mergulho vem crescendo a cada ano estimulado pela enorme extensão da zona costeira brasileira (BRASIL, 2010). Uma das atividades turísticas mais praticadas, no Brasil, é o turismo de mergulho recreativo marinho também denominado de mergulho recreativo subaquático. Em função dessa demanda crescente o Ministério do Meio Ambiente (MMA, 2006) publicou um guia com diretrizes para a visitação não só em ambientes terrestres como aquáticas. No estado de São Paulo há um exitoso programa intitulado "Passaporte para os Roteiros de Mergulho", contendo destinos com á- 
reas de mergulho autônomo, mas em cujas imediações podem ser realizados mergulhos livres. Abrangem Unidades de Conservação (UC's) costeiras, marinhas e insulares. É um produto calcado no programa de ecoturismo da Fundação Florestal de São Paulo, cuja iniciativa denominada de Trilhas de São Paulo alcançou grande sucesso entre seus praticantes (SMA/SP, 2009).

O estado do Rio de Janeiro também comporta inúmeros sítios propícios ao mergulho. Embora dados estatísticos precisos e oficiais sobre o número de merguIhadores com material que permite autonomia submarina inexistam, quer seja por cilindros ou "narguillé" (o ar chega ao mergulhador através de uma longa mangueira), há alguns dados estimados. Pedrini et al. (2007b), afirmaram que existam de 5 à 7 milhões mergulhadores recreativos formados no mundo há cerca de dez anos. O turismo de mergulho tem números significativos. Segundo Augustowski (2007) a indústria do mergulho movimenta anualmente 540 milhões de dólares em venda de equipamentos mundialmente e mais de 1 bilhão de dólares por ano em viagens e turismo. No Brasil, existem cerca de 65 mil e a cada ano são credenciados 15 mil novos mergulhadores recreativos que realizam pelo menos 12 mergulhos por ano e esta atividade movimenta anualmente cerca de $R \$ 11.000 .000,00$ em venda de equipamentos e mais de $\mathrm{R} \$ 26.000 .000,00$ em viagens e turismo (MINISTÉRIO DO TURISMO, 2009).

Segundo Mitraud (2003), as empresas de turismo devem planejar suas atividades tendo em mente todas as vertentes do que se qualifica como Turismo Sustentável. Isto porque as demandas do turismo no mundo contemporâneo estão se voltando para regiões bem preservadas e com maior desigualdade social. Os principais fatores que limitam a atividade do mergulho recreativo no Brasil, abrangem desde as oscilações climáticas e oceânicas sazonais, até a carência de infraestrutura e estatísticas para a atividade (MINISTÉRIO DO TURISMO, 2009).

Tendo em vista que a atividade vem crescendo, torna-se também imprescindível, a análise de seus impactos ambientais tanto positivos como negativos. Em geral o turismo de mergulho marinho é realizado em Unidades de Conservação marinhas, pois a geobiodiversidade, está mais protegida, mantendo suas características originais. Deste modo, conhecendo-se as percepções ambientais dos mergulhadores que, muitas vezes, vão ao fundo do mar em busca de atrativos essencialmente biológicos pode-se mapear seu perfil e suas concepções sobre os impactos ambientais negativos que eles supõem ser possível de causarem.

Para que a prática do ecoturismo marinho possa ser realizada com eficácia deve anteceder a sua instalação a identificação da percepção ambiental dos mergulhadores recreativos que são potenciais usuários desse produto que está sendo desenvolvido atualmente no Brasil (PEDRINI et al. 2011). É tradicional no contexto do ecoturismo se caracterizar a percepção ambiental de seus praticantes tanto antes do início de sua prática (SENNA et al., 2008) como depois (MONTEIRO; ROBIM, 2006) de modo a identificar problemas na sua prática e como solucioná-los. 
Percepção ambiental do mergulhador recreativo no Município do Rio de Janeiro e adjacências: subsídios para a sustentabilidade do ecoturismo marinho

\section{A Percepção Ambiental dos praticantes de mergulho recreativo}

A Percepção Ambiental (PA) é um construto cujo conceito é múltiplo e vem sendo adotado em variadas ciências com o objetivo básico de identificar e caracterizar algum fenômeno ou fato que se pretende compreender e tentar encaminhar soluções, caso haja problema. Neiman (2007) entende que o construto percepção diferencia-se de representação social, podendo ser definido por ação de construir mentalmente representações sobre objetos externos derivados de dados sensoriais. Pedrini et al. (2010a) entendem que as representações sociais são expressões obtidas pela percepção, ou seja, são suas traduções. Independentemente desse debate acadêmico a PA não tem sido muito aplicada no contexto marinho.

No contexto internacional Hannack (2008) utilizou a percepção ambiental como fonte para colher subsídios para uma gestão mais efetiva de uma trilha marinha utilizada por mergulhadores que usam máscara de mergulho e respirador ("snorkelers" em inglês) e também para mergulho autônomo. A autora realizou sua pesquisa no Golfo de Aqaba, no Mar Vermelho numa região pertencente ao Egito onde ocorrem recifes de coral. A motivação dos mergulhadores para essa atividade é estar em contato com a natureza $(96,5 \%)$ e fazer recreação $(86,2 \%)$. O conhecimento que os mergulhadores tinham foi obtido sobre ecologia recifal era na maioria $(73,6 \%)$ com outros mergulhadores seguidos de consulta a livros e jornais $(66,4 \%)$. Os mergulhadores defenderam que a Educação Ambiental Marinha fosse oferecida a eles $(89,9 \%)$ ou numa trilha marinha $(85,8 \%)$. Eles também desejaram equipamentos de apoio como locais sombreados $(79,6 \%)$, banheiros $(73,0 \%)$ e flutuantes $(67,3 \%)$. Assim, além de caracterizar as motivações, conhecimentos prévios e demandas dos mergulhadores a autora pode oferecer subsídios técnicos para uma adequada gestão da trilha marinha.

No Brasil há dois trabalhos emblemáticos sobre o uso da PA para identificar concepções no contexto da biologia marinha. O primeiro de Vasconcelos et al. (2008) apresenta as concepções de alunos de escolas de ensino fundamental e médio sobre o ambiente recifal existente nas praias da cidade de recife, estado de Pernambuco. Concluíram que o conhecimento sobre o tema era muito fraco e só foi aumentado após intervenções de Educação Ambiental marinha feita nas escolas. O segundo de Oigman-Pszczol et al. (2007) cuja pesquisa foi feita na cidade de Armação de Búzios, estado do Rio de Janeiro, mostraram que as pessoas confundiam os corais com algas.

Desse modo, a PA é uma ferramenta muito importante para a caracterização de questões ambientais também no contexto do mergulho recreativo marinho. Como a prática do mergulho marinho normalmente é realizada em unidades de conservação é importante se abordar esse tema.

\section{O mergulho recreativo em Unidades de Conservação Marinhas}

O interesse da população em visitar áreas naturais pouco alteradas tem aumentado ao longo dos anos, incrementando a pressão de visitações em unidades de conservação marinhas. Apesar disso, Augustowski (2007) sustenta que no Brasil, a 
maioria dessas unidades de conservação, criadas há pouco mais de 10 anos, não possuam ainda planos de manejo. Pedrini et al. (2007b) estudaram a partir de anotação de mapas de bordo de escolas e operadoras de mergulho as estatísticas de mergulho recreativo na Reserva Extrativista Marinha de Arraial do Cabo (ResexMarAC) no estado do Rio de Janeiro nessa área protegida. Perceberam que apesar de multas aplicadas pelo chefe da Reserva apenas no máximo nove das cerca de doze escolas/ operadoras enviaram regularmente as estatísticas de mergulho ao Chefe da ResexMarAC no período de 2002-2007. Porém puderam caracterizar essa atividade nessa Unidade de Conservação Marinha (UCM) como: a) maioria dos mergulhadores foi da região sudeste; b) as áreas de mergulho visitadas totalizaram quarenta sendo o predomínio absoluto na llha dos Porcos; c) os dados estatísticos das escolas/operadoras de mergulho apresentaram inconsistências; d) o número de mergulhos aumentou ao longo dos anos, duplicando a cada três deles; e) o nível técnico da maioria dos mergulhadores é apenas básico; f) a durabilidade dos mergulhos predominou entre 30-45 minutos.

É evidente que a estabilidade dos ecossistemas marinhos vem sendo comprometida não só pela pesca predatória como pelo mau uso da zona costeira e as diversas formas de poluição, e também pelo turismo desordenado (MAIDA et al., 1997). Assim, é justificável imputar às operadoras de turismo a responsabilidade não só pela satisfação, segurança e bem estar dos seus clientes, como também pela sustentabilidade da atividade nos âmbitos social, ambiental e cultural da região utilizada (CUNHA; GUERRA, 2003). Augustowski e Francine (2002) publicaram a Carta de Anchieta (por ter sido formulada no Parque Estadual da Ilha Anchieta, estado de São Paulo) apresentando as conclusões de um grande evento que se dedicou a debater modelos de como tornar o mergulho recreativo numa atividade turística sustentável. Um dos trabalhos emblemáticos nesse campo é o de Bertuol (2005) que estudou a Reserva Biológica Marinha do Arvoredo. Ela é uma Unidade de Conservação intensamente visitada e principal destino de mergulho recreativo marinho na região do Mercosul nos últimos anos. Lá o mergulho recreativo se tornou uma atividade turística de grande procura aumentando-se a pressão na integridade física e ecológica desta unidade, reforçando a necessidade de conhecer em detalhes a dinâmica e as interferências desta atividade para a gestão do ambiente subaquático.

\section{O ecoturismo marinho pelo mergulho como ferramenta do turismo sustentável}

Segundo o Ministério do Turismo (2006), pode-se qualificar como turismo ecológico ou ecoturismo, as atividades turísticas que utilizem, de forma sustentável, o patrimônio natural e cultural, incentivando sua conservação e a formação da consciência ambiental através da interpretação do ambiente, promovendo o bem-estar da população humana. O turismo ecológico deve sustentar-se sobre o tripé: interpretação, conservação e sustentabilidade (MINISTÉRIO DO TURISMO, 2009). O debate conceitual sobre ecoturismo tem-se acentuado a medida que esse nome pretende traduzir atividades em área natural com atrativos guardados em UC's. Usualmente ecoturismo no seio acadêmico é compreendido como um produto ou atividade que envolve poucas 
Percepção ambiental do mergulhador recreativo no Município do Rio de Janeiro e adjacências: subsídios para a sustentabilidade do ecoturismo marinho

pessoas, é realizado numa área natural preservada, envolve as comunidades de destino tanto nos aspectos financeiros como na repartição dos benefícios e se realiza interpretação ou educação ambiental (NEIMAN, 2007).

Sendo o ambiente natural a matéria prima a ser explorada como atrativo pelo ecoturismo marinho (LEÃO, 1996; GARROD et al., 2002; PEDRINI et al., 2010c) torna-se imperativa a busca pelo conhecimento sobre os limites socioambientais toleráveis da prática do mergulho recreativo marinho como uma atividade de turismo sustentável. O ecoturismo marinho pode ser desenvolvido pelo mergulho autônomo ou por snorkel. No exterior existem trabalhos importantes que mencionam limites aceitáveis para essa prática que permite aos mergulhadores apreciar a paisagem submarina com seu atrativo principal que é a sua geobiodiversidade. No Brasil ainda não se conhece que organismos ou rochas especificamente podem ser indicadores de impacto causado por mergulhadores em atividade turística. Porém já se sabe que tipos de impactos ambientais negativos são causados essencialmente nos costões rochosos pelo turismo em geral como por mergulhadores em geral, turistas de sol e praia ou banhistas. Os indicadores mais estudados são: a) ressuspensão de sedimentos (BERCHEZ et al., 2005); b) pisoteamento de organismos (PEDRINI et al., 2008); c) remoção de organismos (SILVA; GHILARDILOPES, 2012); d) alteração de características ecológicas de comunidades de algas bentônicas (SILVA et al., 2012)

A gestão socioambiental da atividade do mergulho recreativo marinho em UC's e seus eventuais impactos negativos têm sido realizados, considerando-se as seguintes alternativas: a) redução do número de mergulhos por área (HAWKINS et.al. 1999); b) determinação da capacidade de carga por unidade de área (WEDEKIN, 2003); c) fechamento de áreas de mergulho e sua transferência para territórios alternativos (PEDRINI et al. 2007a); d) realização de educação ambiental nas embarcações dos mergulhadores (MEDIO et al. 1997) ou no próprio local de mergulho (BERCHEZ et al., 2007).

O ecoturismo marinho se ajusta aos preceitos tradicionais do ecoturismo terrestre e assim ele tende a ser realizado de forma sustentável, em tese. Porém, como visto acima o mergulho recreativo que pode agregar impactos ambientais positivos pela geração de renda e impostos também pode ser negativo, trazendo malefícios aos seus atrativos. Desse modo, informações sobre o perfil, a estrutura e a dinâmica dos mergulhadores certamente poderá fornecer subsídios importantes para a criação de políticas públicas.

O presente trabalho procurou analisar o perfil do turista que pratica o merguIho subaquático e das suas escolas/operadoras no município do Rio de Janeiro pela percepção ambiental dos impactos do mergulho recreativo nos ecossistemas costeiros, visando fornecer subsídios técnicos para a otimização da atividade. Assim sendo a medida que o ecoturismo marinho for sendo implantado se conhecerá previamente os potenciais impactos ambientais negativos de seus prováveis praticantes. 


\section{Metodologia}

Para a coleta de dados primários que caracterizassem os empreendimentos relacionados ao turismo submarino no município do Rio de Janeiro e os mergulhadores recreativos que visitassem pontos de mergulho no litoral do município supracitado, foram elaborados questionários específicos com questões abertas e fechadas, destinados ao preenchimento por gestores de empresas e escolas e mergulhadores recreativos.

Quatro diferentes estratégias foram utilizadas para a distribuição dos questionários destinados aos mergulhadores recreativos: $1^{\text {a }}$ Envio por e-mail para pessoas do circulo de conhecimentos dos autores (mais de 500 mensagens, além de re-envios não conhecidos), $2^{\text {a }}$ Disponibilização em um blog de uma operadora de mergulho, $3^{\text {a }}$ Disponibilização em comunidade de mergulho recreativo no site de relacionamentos Orkut, $4^{\mathrm{a}}$ Entrega de questionários impressos em mãos.

Para a distribuição dos questionários destinados ao preenchimento pelos gestores das operadoras /escolas foram utilizadas as mesmas estratégias, sendo que, na estratégia de envio de formulários via e-mail, estes foram remetidos para 54 empresas do total de 91 das existentes no município do Rio de Janeiro. Os dados obtidos através dos questionários foram digitados em planilha eletrônica, para a sua análise estatística através da interpretação de gráficos e testes de significância (Qui-quadrado, $p<0,1$ ), segundo Zar (1999).

\section{Resultados}

\section{Obtenção da amostra}

Ao final de dois meses de espera, foram obtidos como resposta aos mais de 500 emails enviados, treze questionários preenchidos. A partir dos questionários disponibilizados no blog, foram obtidos oito questionários; do universo de mais de oito mil membros da comunidade de mergulho do Orkut, três se dispuseram a responder e enviar os questionários; dos 27 questionários impressos entregues em mãos, foram devolvidos 11 questionários preenchidos (Tabela 1). Obtendo-se um total de 35 questionários respondidos. Essa baixa resposta tem sido comum em pesquisas (PEDRINI, 2007).

Tabela 1: Número de questionários preenchidos por mergulhadores recreativos de acordo com a sua estratégia de distribuição.

Table 1: Number of questionnaires filled by recreational divers according to the applied strategy of distribution.

\begin{tabular}{lcc}
\hline \multicolumn{1}{c}{ Estratégia } & Universo de mergulhadores & $\begin{array}{c}\text { Questionários } \\
\text { preenchidos e devolvidos }\end{array}$ \\
\hline E-mail & $>500$ & 13 \\
Blog & Não definido & 8 \\
Comunidade do Orkut & $>8.000$ & 3 \\
Impressos & 27 & 11 \\
Total & $>8.527$ & 35 \\
\hline
\end{tabular}


Percepção ambiental do mergulhador recreativo no Município do Rio de Janeiro e adjacências: subsídios para a sustentabilidade do ecoturismo marinho

Por sua vez, os questionários respondidos por gestores das 54 operadoras/ escolas contatadas por email, totalizaram sete, sendo que seis destes foram impressos, preenchidos e entregues pelos gestores em visitas as empresas agendadas após o contato por e-mail. Um foi enviado por e-mail por um gestor que tomou conhecimento da pesquisa no site de relacionamento Orkut.

\section{Perfil dos mergulhadores recreativos}

O maior número de indivíduos, tanto do sexo masculino $(n=18)$ como do sexo feminino $(n=17)$ com o curso superior completo foi evidente, respectivamente, em números de 12 e 10 seguido por pós-graduação, em número de 2 e 4 . Demonstra que a atividade de mergulho é praticada, em sua maioria, por indivíduos que possuem qualificação acadêmica e provavelmente maior renda e nível de instrução (Figura 1).

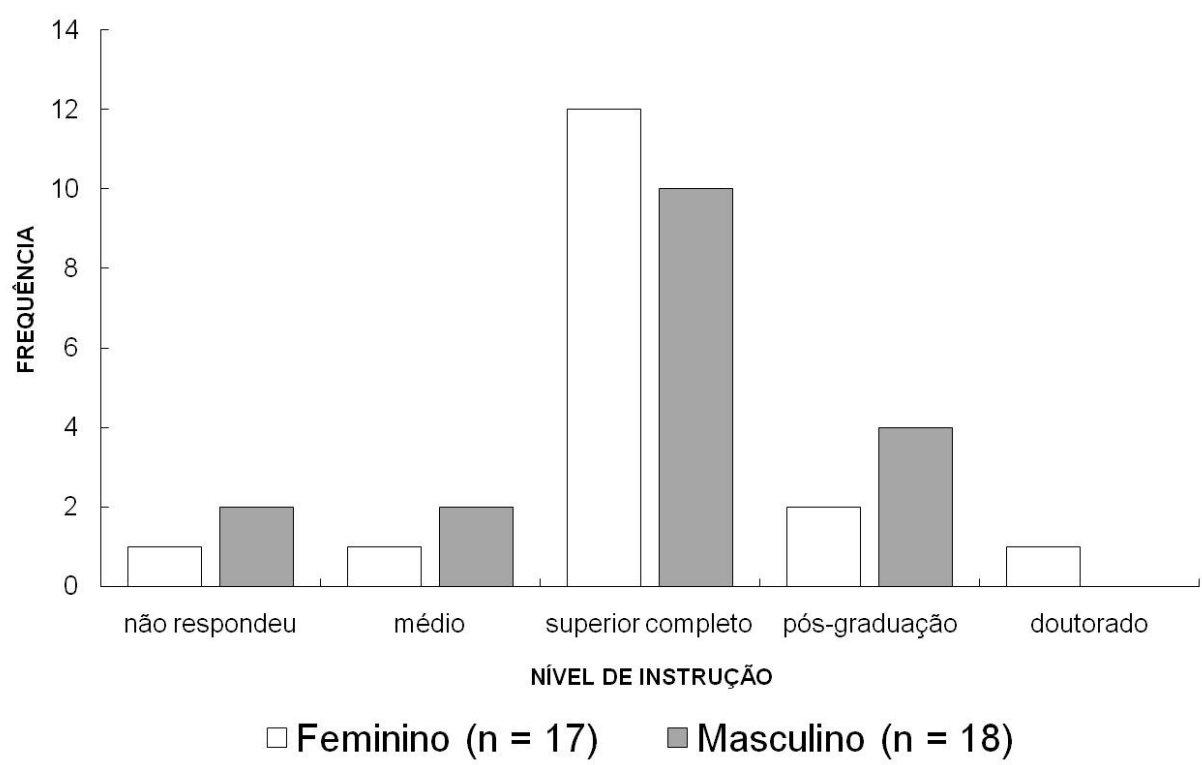

Figura 1: Frequência de mergulhadores recreativos da amostra de acordo com o sexo e o nível de instrução.

Figure 1: Number of sampled recreational divers according to sex and graduation.

Os que possuem renda familiar de 1 à 3 salários mínimos não gastam com saídas e fazem gastos muito baixos na aquisição de equipamentos, sugerindo que realizem saídas sem o intermédio de operadoras e praticando o mergulho livre, os que têm renda familiar de 3 à 6 salários mínimos gastam significativamente (Qui-quadrado, $\mathrm{X}^{2}=$ $238,1, p<0,1 \%$ ) menos com saídas do que com equipamentos, enquanto que os que possuem renda familiar de 6 à 9 e de mais de 9 salários mínimos fazem maiores gastos com saídas. (Figura 2). 


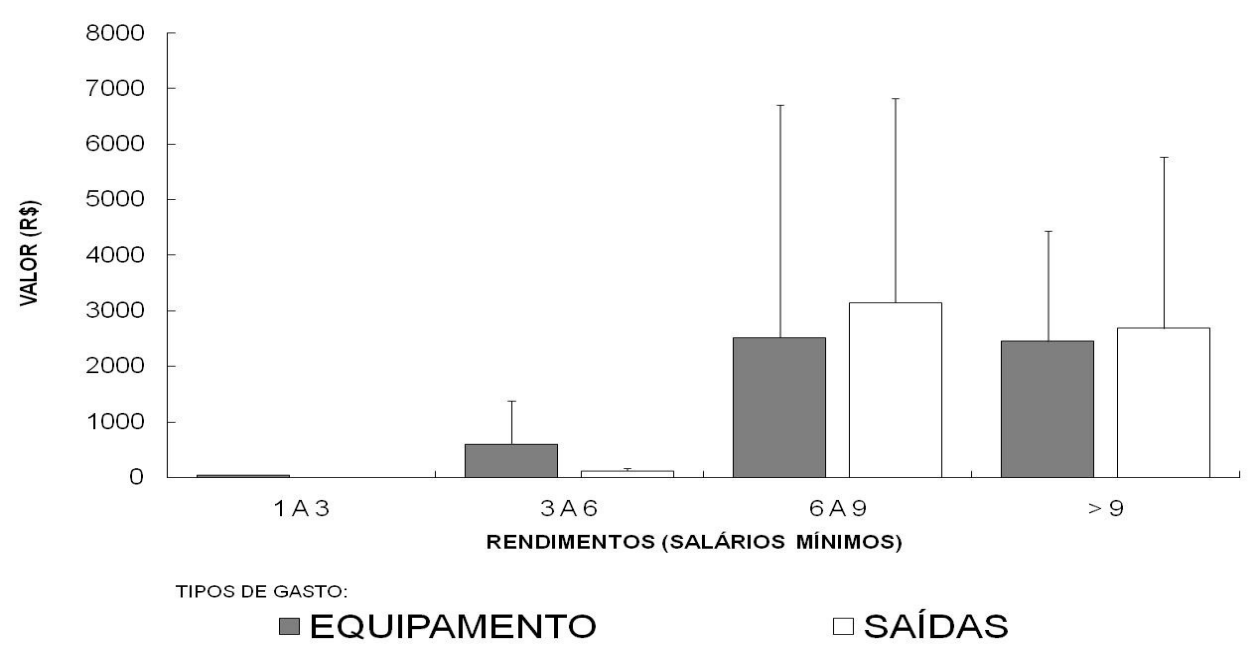

Figura 2: Valores médios ( \pm desvio padrão) em Reais gastos com compra de equipamentos e saídas de mergulho por faixas de rendimento (salários mínimos).

Figure 2: Mean values ( \pm standard error) in Reais spent in equipment and diving trips according to income.

A faixa etária que realiza maiores gastos com equipamentos, em relação a gastos com saídas, é de 20 a 30 anos. Os gastos significativamente maiores (Qui-quadrado, $\mathrm{X}^{2}=$ $1146,5, p<0,1 \%$ ) com saídas ocorrem para os indivíduos que possuem de 30 e 40 e de 40 e 50 anos. A relação entre maiores gastos com saídas a partir da faixa etária de 30 a 40 pode estar relacionado ao fato de que nesta faixa etária os indivíduos já dispõem de equipamentos adequados. A faixa etária acima de 50 anos foi composta por um único indivíduo, não existindo assim parâmetro de comparação com as demais faixas (Figura 3).

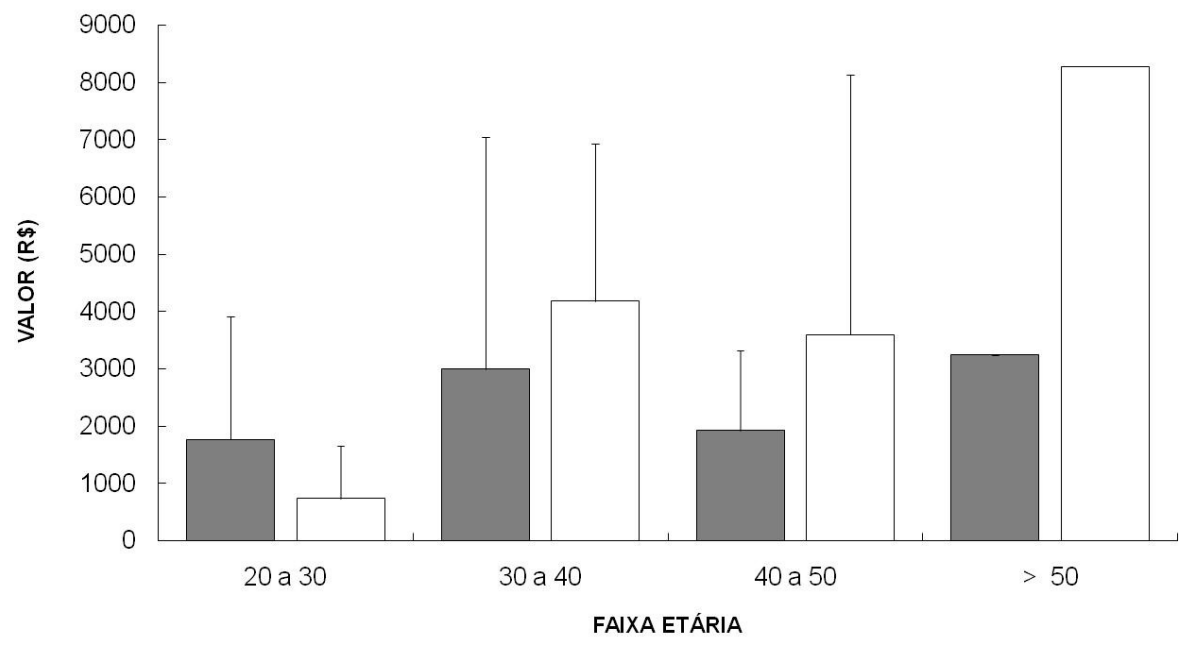

TIPOS DE GASTO:

$\square$ EQUIPAMENTO

$\square$ SAÍDAS

Figura 3: Valores médios ( \pm desvio padrão) em Reais gastos com compra de equipamentos e saídas de mergulho por faixas etárias (anos).

Figure 3: Mean values ( \pm standard error) in Reais spent in equipment and diving trips according to age. 
Percepção ambiental do mergulhador recreativo no Município do Rio de Janeiro e adjacências: subsídios para a sustentabilidade do ecoturismo marinho

\section{A percepção dos impactos ambientais negativos do mergulho}

Os mergulhadores que possuem uma ou nenhuma qualificação, relataram tocar mais o fundo em relação aos indivíduos que possuem uma ou mais qualificações, isso evidencia que a falta de instrução e a pouca experiência indicam/sugerem fatores importantes para o maior impacto ambiental da atividade (Figura 4).

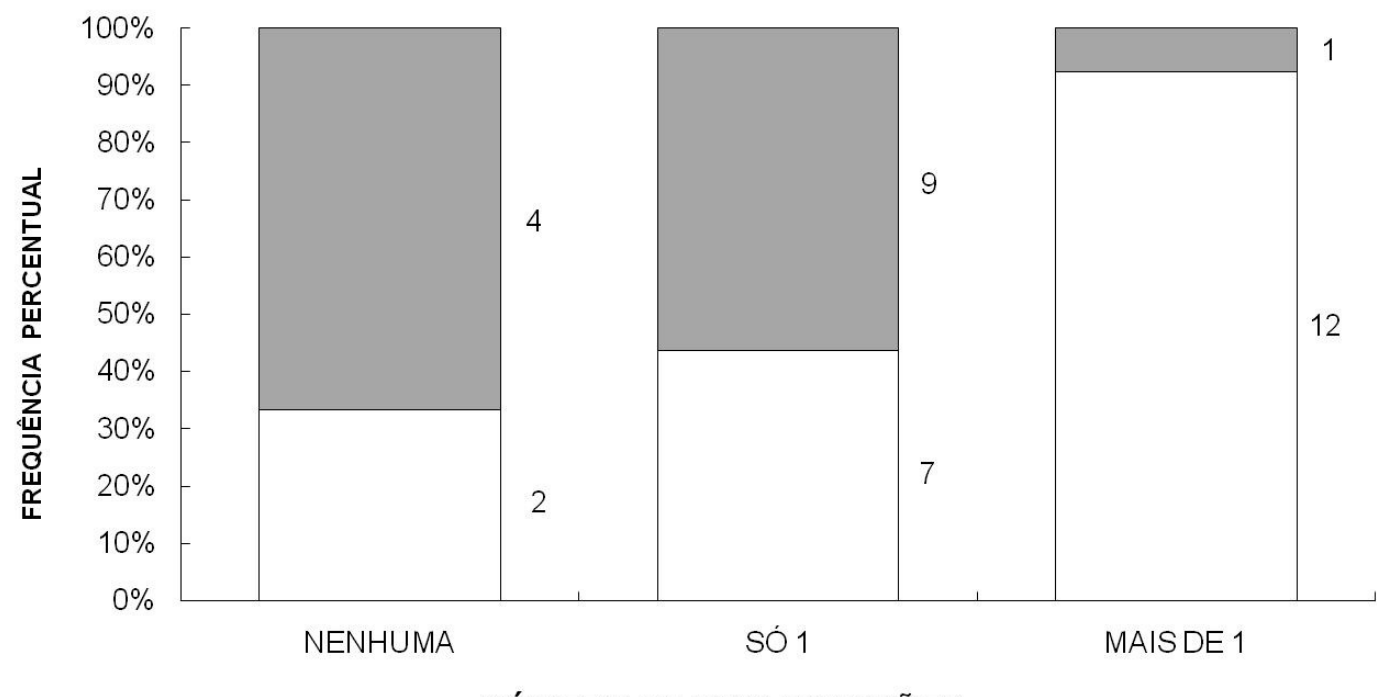

NÚMERO DE QUALIFICAÇÕES

FREQUENCIA DE TOQUES NO FUNDO:

$$
0 \text { A } 4 \quad \square>4
$$

Figura 4: Frequência percentual e absoluta (valores ao lado das barras) de citações de toques no fundo pelos mergulhadores de diferentes números de qualificações.

Figure 4: Percent an absolute (right side of vertical bars) frequency of citation of bottom touching by divers according to their level of qualification.

Também se pode observar que existe uma relação inversa entre o número de qualificações e a freqüência com que os mergulhadores afirmaram revolver o fundo. Dos indivíduos que possuem uma qualificação $75 \%$ revolvem o fundo raramente, $20 \%$ com pouca freqüência e $5 \%$ frequentemente. Dos que não possuem qualificação $25 \%$ revolvem o fundo raramente, $50 \%$ com baixa freqüência e $25 \%$ frequentemente (Figura 5).

\section{Percepção dos impactos negativos da atividade do mergulho}

Dos impactos ambientais específicos da atividade do mergulho assinalados pelos mergulhadores, o mais frequente é a interação dos próprios mergulhadores com a biota, o que se deve certamente ao desconhecimento e o fácil acesso aos equipamentos básicos. A poluição oriunda dos barcos utilizados para mergulho foi o segundo problema mais assinalado. Percebe-se que os locais de maior visitação são a Costa Azul e a Costa Verde do Rio de Janeiro e à julgar pelos questionários, estes são os 
Brotto, D.S.; Pedrini, A.G.; Bandeira, R.R.C.; Zee, D.M.W.

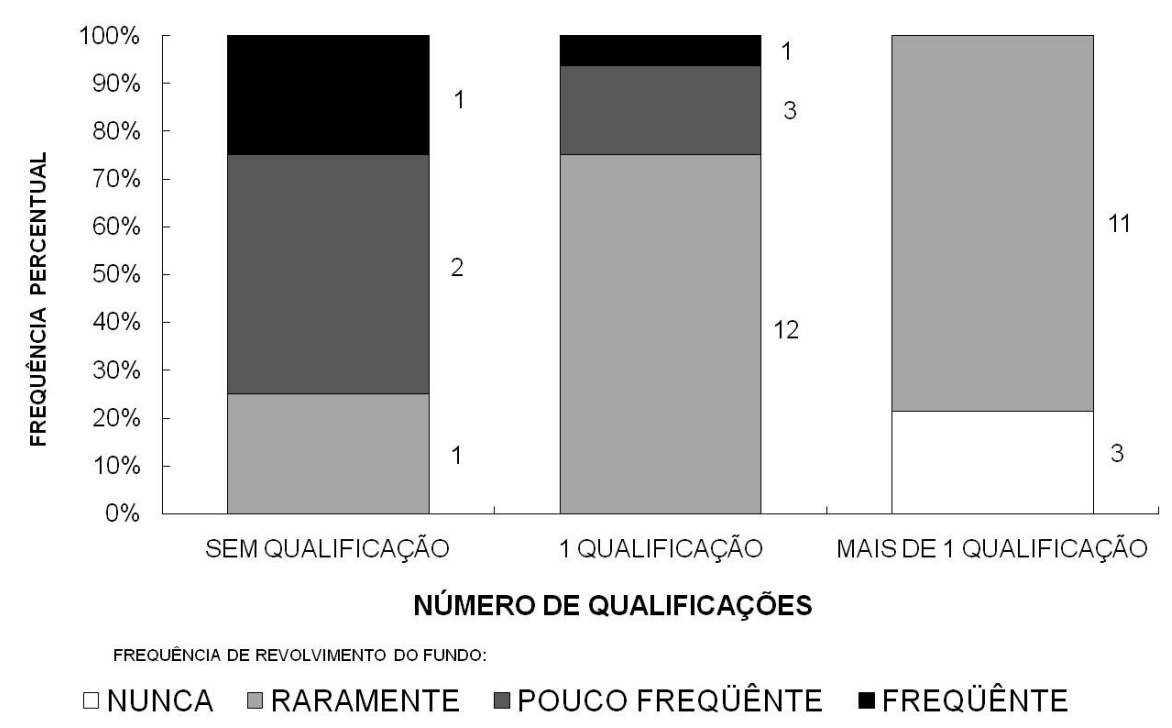

Figura 5: Frequência percentual e absoluta (valores ao lado das barras) de citações de revolvimento do fundo pelos mergulhadores de diferentes números de qualificações.

Figure 5: Percent an absolute (right side of vertical bars) frequency of citation of sediment revolving by divers according to their level of qualification

locais onde mais impactos ambientais são apresentados. Nessas regiões o excesso de visitantes apareceu como o quinto maior problema, assim como, a suspensão de sedimento e a ancoragem feita em local e de maneira errada também só foram notados nessas regiões (Figura 6). ]

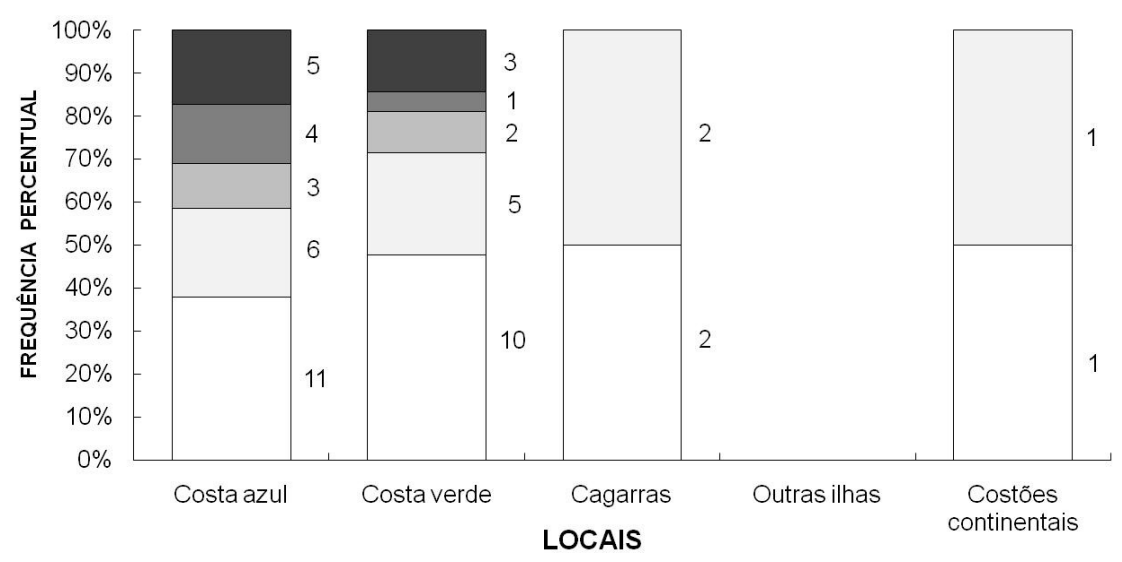

TIPOS DE IMPACTO:

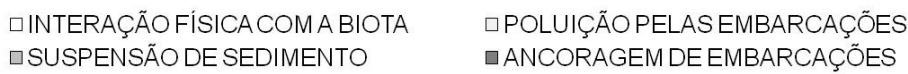

-EXCESSODE VISITANTES

Figura 6: Frequência percentual e absoluta (valores ao lado das barras) de citações de impactos do mergulho por região.

Figure 6: Percent an absolute (right side of vertical bars) frequency of citation diving impacts by region (dive sites). 
Percepção ambiental do mergulhador recreativo no Município do Rio de Janeiro e adjacências: subsídios para a sustentabilidade do ecoturismo marinho

\section{Percepção dos impactos negativos em geral}

Em todas as regiões a presença de resíduos sólidos foi o impacto mais citado, os resíduos facilmente se evidenciam, pois desagradam os mergulhadores, afetando a estética dos sítios subaquáticos. A pesca em locais de mergulho foi também assinalada, consistindo em fonte de risco aos mergulhadores e impacto direto à comunidade marinha. A presença de bioinvasores e o aumento da temperatura da água também foram mencionados, de acordo com esses depoimentos a região da Costa verde seria a mais impactada, porém isso só se deve ao maior número de visitações para essa região (Figura 7).

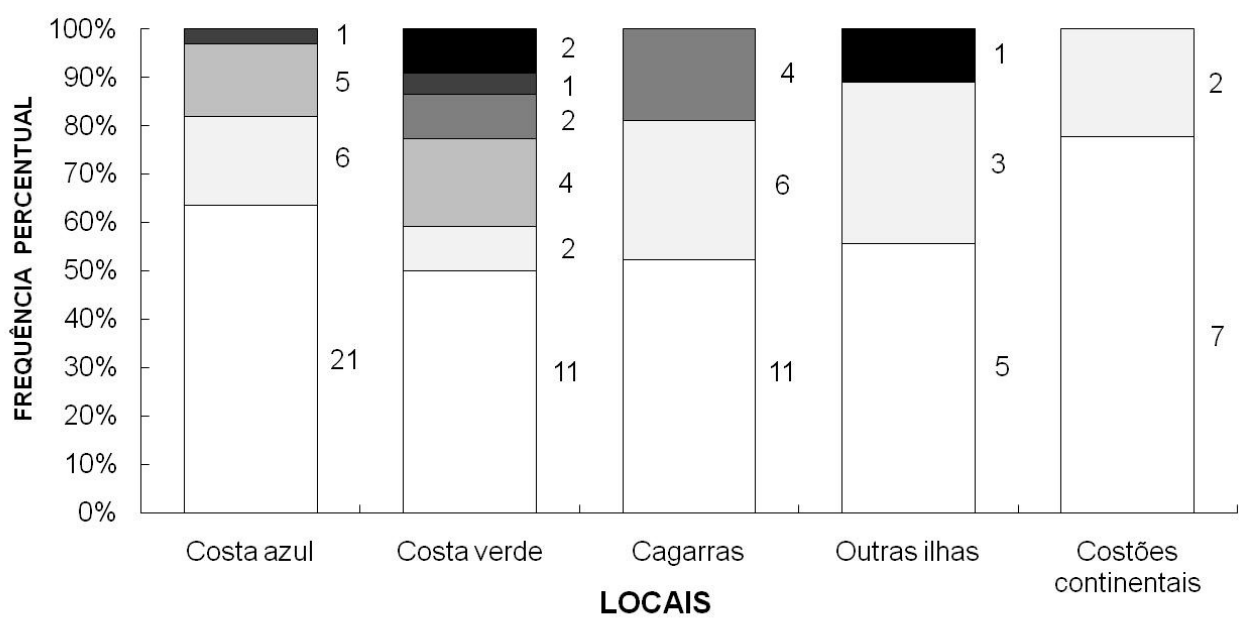

TIPOS DE IMPACTO:

口RESIDUOS SÓLIDOS

$\square$ PESCA

$\square B I O I N V A S O R E S$

-AUMENTO DA TEMPERATURA

$\square$ REDUÇÃODABIODIVERSIDADE

- AUMENTO DA TURBIDEZ

Figura 7: Frequência percentual e absoluta (valores ao lado das barras) de citações de impactos genéricos por região.

Figure 7: Percent an absolute (right side of vertical bars) frequency of citation of specific generic impacts by region (dive site).

Aparentemente os gestores subestimam os impactos proporcionados pela própria operadora, esses impactos devem-se à ausente ou precária orientação e supervisão dos mergulhadores, embora todos os gestores se preocupem em citar que o mergulhador não deve tocar o fundo. Suas respostas também não evidenciaram adequadamente quais as ações inerentes aos mergulhadores ou à operadora (Tabela 2).

Na ocasião do acompanhamento da aula prática, realizada na Urca, ocorreram dois mergulhos, no retorno do primeiro o instrutor perdeu sua câmera fotográfica, denotando que a perda de objetos durante o mergulho seja comum. No segundo mergulho foi observado dificuldades em relação à estabilidade na água pe- 
los alunos, atribuídos a inexperiência e a falta de adequação aos equipamentos alugados, não obstante, o instrutor foi veemente em alertá-los que evitassem tocar nos organismos e no fundo.

Tabela 2: Frequência de citações pelos gestores de operadoras de atitudes e procedimentos tidos como boas práticas do mergulho recreativo.

Table 2: Percent and absolute frequency of citation of good diving practices and attitudes according to dive school managers sampled.

\begin{tabular}{lcc}
\hline \multicolumn{1}{c}{ ATITUDE/PROCEDIMENTO } & \multicolumn{2}{c}{ FREQUENCIA } \\
\cline { 2 - 3 } & ABSOLUTA & PERCENTUAL \\
\hline Não tocar no fundo & 7 & 29,2 \\
Recolher o seu lixo & 3 & 12,5 \\
Evitar óleo na água & 3 & 12,5 \\
Ancorar corretamente & 3 & 12,5 \\
Não revolver o fundo & 2 & 8,3 \\
Não interagir com a biota & 2 & 8,3 \\
Não coletar nada & 2 & 8,3 \\
Supervisão & 1 & 4,2 \\
Lastro correto & 1 & 4,2 \\
\hline TOTAL & 24 & 100 \\
\hline
\end{tabular}

\section{Discussão}

O baixo retorno dos questionários tem sido uma constante em pesquisas em que se adota envio de cartas ou mensagens por e-mails (PEDRINI, 2007). No entanto, o presente estudo, de caráter exploratório, se baseia em um número adequado para um levantamento preliminar. Os mergulhadores têm um nível alto de escolaridade, ou seja, maioria absoluta de ensino superior (Fig. 1). O perfil dos respondentes aderiu a expectativa de que os praticantes de mergulho autônomo possuem um nível salarial típico da classe média (Fig. 2). Tal fato se consubstancia porque os mergulhadores da faixa de 30-40 anos são os que mais investem na compra de equipamentos e saídas para mergulhar (Fig.3) talvez porque nessa faixa já estariam empregados.

Em termos de impacto ambiental negativo do mergulho seus praticantes com pouca ou nenhuma qualificação, ou seja, do nível básico relataram tocar e revolver mais o fundo, inclusive acima dos outros mais qualificados (Figs. 4/5). Como afirmaram Pedrini et al. (2007b) ao estudar os mergulhadores da Reserva Marinha Extrativista de Arraial do Cabo cerca de $54 \%$ deles eram do nível básico. Silva e Ghilardi-Lopes (2012) ao entrevistarem turistas que mergulhavam em duas áreas marinhas do litoral paulista notaram que esse tipo de turista não tem nenhuma consciência dos impactos negativos que podem causar, tais como o pisoteio em organismos marinhos. Desse modo pode-se inferir que os turistas mergulhadores podem causar impacto ambiental negativo marinho, porém a maioria não tem essa noção. E sendo mergulhadores inexperientes e pouco qualificados isso pode causar mais estragos ambientais ao mar.

Ao se analisar a percepção dos mergulhadores quanto a especificidade de 
Percepção ambiental do mergulhador recreativo no Município do Rio de Janeiro e adjacências: subsídios para a sustentabilidade do ecoturismo marinho

seus impactos ambientais negativos vislumbrou-se que há um excesso de visitação turística tanto nas costas verde (Angra dos Reis e arredores) ou azul (Região dos lagos) que coincide com os maiores impactos ambientais negativos como ressuspenssão de sedimentos e interação com a biota marinha (Fig.6). Assim, associando maiores impactos ambientais negativos em áreas com maior afluxo de turistas o resultado é preocupante. Isso se confirma com os resultados de Pedrini et al. (2010b) e Silva e Ghilardi-Lopes (2012), pois eles afirmaram que os turistas não tinham ideia de que o pisoteio, coleta ou quebra de organismos dos costões seria um impacto ambiental negativo.

Ao se abordar a questão de impactos ambientais negativos de modo global os resíduos sólidos despontam como o maior dos problemas, face ao incômodo estético na água. Em seguida, a pesca foi apontada tanto como fonte de risco ao mergulhador como responsável direta pelo impacto negativa na área. Seguiu-se a presença de bioinvasores e o aumento da temperatura da água. A existência de animais e algas invasoras é patente na costa verde em que há duas espécies de coral do gênero Tubastrea expandindo-se na Baía de Ilha Grande (DE PAULA; CREED, 2004). O aumento da temperatura da água causa estranheza, pois esse fato não é comum. Ao contrário, ocorre o fenômeno da ressurgência na costa azul (BRASILEIRO et al.,2009) que aumenta a biodiversidade marinha da região dos lagos, especialmente as algas marinhas bentônicas.

Os gestores das escolas/operadoras de mergulho listaram atitudes/ procedimentos que consideraram boas práticas do mergulho recreativo, predominando não tocar o fundo $(29,2 \%)$. Apesar de na formação dos mergulhadores essa atitude ser muito enfatizada, o que se constatou no presente trabalho é o oposto, com predomínio desse impacto negativo principalmente com os mergulhadores com baixa qualificação.

Uma sugestão a ser proposta na capacitação dos mergulhadores é a inclusão no seu curso de matéria sobre impactos ambientais negativos do turismo de merguIho. Em paralelo deveria também ser incluída na formação deles fundamentos de educação ambiental marinha (BERCHEZ et al., 2005; SILVA; GHILARDI-LOPES, 2012). Essa atividade poderia ser realizada também nas embarcações sob a forma de preleções tal como já foi provado por autores que minimiza ou extingue os impactos (MEDIO et al.,1997; PEDRINI et al., 2008). Para que o turismo subaquático possa ser desenvolvido de forma sustentável e responsável, são necessárias medidas como a fiscalização, a integração de ações das certificadoras, operadoras, escolas de merguIho, órgãos ambientais, universidades, Organizações não Governamentais de cunho conservacionista, além da comunidade local (MITRAUD, 2003; MINISTÉRIO DO TURISMO, 2009).

A Educação Ambiental Marinha (EAM) através de preleções, segundo Dixon e Sherman (1990), pode ampliar em até 50\%, a capacidade de carga dos sítios subaquáticos para a visitação. Inúmeros colegas vêm sugerindo a adoção imediata da EAM nos variados contextos de uso público do litoral, como em UC's e áreas sujeitas a impacto ambiental negativo imediato (BERCHEZ et al. 2005; SILVA; GHILARDILOPES, 2012). Outros autores enfatizaram que preleções aos mergulhadores embar- 
cados antes de mergulharem é capaz de mudar radicalmente o comportamento predatório do mergulhador (MEDIO et al. 1997; TOWNSEND 2000; BERCHEZ et al. 2005; PEDRINI et al. 2010b). Tal medida mostra que a adoção de ações/atividades permanentes de conscientização eficazes minimiza ou evita os impactos ambientais negativos causados pelos mergulhadores. Essa atitude possibilita uma maior capacidade de carga nos sítios de mergulho sem impacto ambiental negativo importante. Desse modo, as escolas/operadoras de mergulho não têm prejuízo pela diminuição do número de mergulhadores que podem comprar/alugar material de mergulho.

\section{Considerações Finais}

Essa pesquisa possibilitou a enumeração dos seguintes subsídios técnicos: 1ำ A necessidade urgente da inclusão de conteúdos sobre os ecossistemas aquáticos nos cursos do nível básico à dive-master, na forma de preleções com reforço de materiais impressos; 2ำ Dar especial atenção por parte dos guias e instrutores aos iniciantes e mergulhadores com qualificação básica.;3ํㅡㄴ instrução de novos alunos, batismos subaquáticos e visitação por mergulhadores básicos; 4ํㅡㅁ Obrigar o uso correto do colete hidrostático; $5^{\circ}$ Inserir treinamentos para 0 correto deslocamento submerso nos cursos de capacitação em mergulho; 6 Realizar preleções sobre a estrutura e dinâmica dos ecossistemas subaquáticos antes de qualquer mergulho realizado por um grupo de alunos de mergulho ou turistas; $7^{\circ}$ Realizar, por parte das certificadoras, permanentemente o acompanhamento e avaliação constante do trabalho realizado pelos guias e instrutores. A adoção dessas simples medidas pelos profissionais do setor do mergulho recreativo trará inúmeros benefícios para o próprio setor e a integridade dos ecossistemas visitados, possibilitando no futuro a prática de um ecoturismo marinho sustentável.

A prática do ecoturismo marinho demandará dos mergulhadores comportamentos próprios de guardiões do mar e não de predadores subaquáticos. Desse modo, ainda existe tempo para aperfeiçoar a formação de novos mergulhadores que serão os potenciais condutores, guias ou incentivadores desse novo modelo de ecoturismo.

\section{Referências Bibliográficas}

AUGUSTOWSKI, M. Atividades de Mergulho como Ferramenta de Conservação em áreas marinhas protegidas: avanços e desafios. In: CARBOJIM, J. B. P. Estratégias de Conservação da Biodiversidade no Brasil. Rede Marinho-Costeira e Hídrica do Brasil, 2007, pp. 58-63.

AUGUSTOWSKI, M.; FRANCINE JR., R., O mergulho recreacional como ferramenta para o turismo sustentável em unidades de conservação marinhas. In: CONGRESSO BRASILEIRO DE UNIDADES DE CONSERVAÇÃO, 3., Anais..., 2002, Rede ProUC, Fortaleza, pp. 443-452.

BERCHEZ, F.A.S.; CARVALHAL, F.; ROBIM, M.J. Underwater interpretative trail: guidance to improve education and decrease ecological damage. International Journal of Environment and Sustainable Development, v. 4, pp.128-139. 2005. 
Percepção ambiental do mergulhador recreativo no Município do Rio de Janeiro e adjacências: subsídios para a sustentabilidade do ecoturismo marinho

BERCHEZ, F.; GHILARDI, N.; ROBIM, M. de J.; PEDRINI, A. de G.; HADEL, V. F.; FLUKIGER, G.; SIMÕES, M.; MAZZARO, R.; KLAUSENER, C., SANCHES, C.; BESPALEC, P. Projeto trilha Subaquática - Sugestão de diretrizes para a criação de modelos de Educação Ambiental para ecossistemas marinhos. OLAM, Ciência e Tecnologia, Rio Claro (SP), v.7, n. 2, pp.181-208, 2007.

BERTUOL, P.R.K., Efeitos de atividades de Mergulho Autônomo sobre um ambiente de Costão Rochoso. 2005. Dissertação para obtenção de grau em Mestre em Ciências e Tecnologia Ambiental. Universidade do Vale do Itajaí, Centro de Ciências Tecnológicas, da Terra e do Mar. Itajaí, SC, 2005.

BRASIL. Mensagem ao Congresso Nacional. Brasília: Presidência da República, 2010.

BRASILEIRO, P. S.; YONESHIGUE-VALENTIN, Y.; BAHIA, R. da G.; REIS, R. P.; AMADO FILHO, G. M. Algas Marinhas Bentônicas da Região de Cabo Frio e Arredores: Síntese do Conhecimento. Rodriguesia, Rio de Janeiro, v. 60, n.1, pp. 39-66, 2009.

CUNHA, S. B.; GUERRA, A. J. T. A questão ambiental: Diferentes abordagens. Rio de Janeiro: Bertrand Brasil, 2003.

DE PAULA, A.F.; CREED, J.C. Two species of the coral Tubastraea (Cnidaria, Scleractinia) in Brazil: a case of accidental introduction. Bulletin of Marine Science, v. 74, pp 175-183, 2004.

DIXON, J. A.; SHERMAN, P.B. Economics of Protected Areas. Londres: Earth Scans, 1990.

GARROD, B.; WILSON, J. C.; BRUCE, D. M. Ecoturismo Marino Genuinamente Sostenible en el Área Atlântica de La UE: Guia de Buenas Prácticas. Bristol: University of the Weast of England, 2002, $81 \mathrm{p}$.

HANNAK, J. S. A snorkel trail based on reef condition and visitor perception as a management tool for a threatened shallow water reef in Dahab (South Sinai, Egypt). Tese (Magistra der Naturwissenschaften), Universität Wien, 2008, 54 p.

HAWKINS, J.P; ROBERTS, C.M.; HOF, T.V.; MEYER, K. D.; TRATALOS, J.; ALDAM, A.C.; 1999. Effects of Recreational Scuba Diving on Caribbean Coral and Fish Communities. Conservation Biology, v.. 13, n. 4, Aug/1999, pp 888-897

LEÃO, Z. M. A. N. The coral reefs's of Bahia: morphology, distribution and major environmental impacts. Anais da Academia Brasileira de Ciências, Rio de Janeiro, v. 68, n.3, pp. 439-452, 1996.

MAIDA, M.; PAULA-PONTES, A. C.; FERREIRA, B. P.; CASTRO, C. B.; PIRES, D. O. ; RODRIGUES, M. C. M. (Org.) Relatório do Workshop sobre os Recifes de Coral Brasileiros: Pesquisa, Manejo Integrado e Conservação. Tamandaré: CEPENE/IBAMA/ Coralus. 1997.

MEDIO, D. ; ORMOND, R.F.G. ; PEARSON, M., Effect of briefings on rates of damage to corals by scuba divers. Biological Conservation, v.79, pp.91-95. 1997.

MINISTÉRIO DO MEIO AMBIENTE. Diretrizes para Visitação em Unidades de Conservação. Brasília: Secretaria de Biodiversidade e Florestas, Serie Áreas Protegidas, 2006, 72 p.

MINISTÉRIO DO TURISMO (MTur). Conceitos básicos e apoio à comercialização de produtos segmentados. Brasília: MTur, 2009, 208 p.

MITRAUD, S. (Org.) Manual de Ecoturismo de Base Comunitária: ferramentas para um planejamento responsável. Brasília, WWF, 2003, pp. 33-68. 
MONTEIRO, P. O.; ROBIM, M. de J. participação e Percepção da comunidade local no desenvolvimento do ecoturismo no bairro do Cambury, Parque Estadual da Serra do Mar - Núcleo de Picinguaba, Ubatuba, SP. OLAM Ciência e Tecnologia, Rio Claro (SP), v. 6, n. 1, pp 161-181, mai. 2006.

NEIMAN, Z. Percepção e representações: aspectos da psicologia ambiental. In: ENCONTRO DE PESQUISA EM EDUCAÇÃO AMBIENTAL, 4., Anais..., 2007, pp.1-34.

OIGMAN-PSZCZOL, S. S; OLIVEIRA, A. E. S., CREED. J. C Perceptions of coral in a coastal tourist town in Brazil. Coral Reefs, Den Burg, 26, pp.667-670, 2007.

PEDRINI, A. de G. Um caminho das pedras. In: PEDRINI, A. de G. (Org.) Metodologias em Educação Ambiental. Petrópolis: Vozes, 2007, pp. 23-51.

PEDRINI, A.G.; COSTA, C.; NEWTON, T.; MANESCHY, F.S.; SILVA, V.G.; BERCHEZ, F.; SPELTA, L.; GHILARDI, N.P.,; ROBIM, M.J., Efeitos ambientais da visitação turística em áreas protegidas marinhas: estudo de caso na Piscina Natural Marinha, Parque Estadual da Ilha Anchieta, Ubatuba, São Paulo, Brasil. Revista OLAM e Ciência e Tecnologia, v.7, pp.678-696. 2007.

PEDRINI, A. G.; MANESCHY, F. S. A.; COSTA, C.; ALMEIDA, E. R.; ANDRADE-COSTA, E. Gestão ambiental em áreas protegidas $x$ estatísticas de mergulho na Reserva Extrativista Marinha de Arraial do Cabo, RJ. OLAM - Ciência e Tecnologia, Rio Claro (SP), v. 7, n.2, p. 269 -294, 2007b.

PEDRINI, A. de G., COSTA, C., SILVA, V.G., MANESCHY, F.S., NEWTON, T., BERCHEZ, F., GHILARDI, N.P., SPELTA, L., Gestão de Áreas Protegidas e efeitos da visitação ecoturística pelo mergulho com snorkel: o caso do Parque Estadual da Ilha Anchieta (PEIA), Estado de São Paulo. Revista Eletrônica do Mestrado em Educação Ambiental (REMEA), v. 20, pp.1 -20. 2008.

PEDRINI, A. de G.; ANDRADE-COSTA, E.; GHILARDI, N. P. Percepção ambiental de crianças e pré-adolescentes em vulnerabilidade social para projetos de educação ambiental. Revista Ciência e Educação, Bauru, v.16, n.1, pp. 163-179, 2010a.

PEDRINI, A. de G.; MANESCHY, F. S. A.; SILVA, V. G.; NEWTON, T.; CAMPOS, P. H.; COSTA, C.; ANDRADE-COSTA, E. EduMar - Projeto de educação/interpretação ambiental marinha para o mergulho recreativo. In: PEDRINI, A. de G. (Org.). Educação Ambiental Marinha e Costeira no Brasil. Rio de Janeiro: EdUERJ, 2010b, pp. 143-167.

PEDRINI, A. de G.; MESSAS, T.; PEREIRA, E. da F.; GHILARDI, N. P.; BERCHEZ, F. Educação ambiental pelo ecoturismo numa trilha marinha no Parque Estadual da Ilha Anchieta, Ubatuba, São Paulo, Brasil. Revista Brasileira de Ecoturismo, São Paulo, v.3, n.3, pp.428459. 2010c. Disponível em: <http://www.sbecotur.org.br/rbecotur/seer/index.php/ecoturismo/ article/view/97/50>. Acesso em: 01.02/2012.

PEDRINI, A. de G.; BROTTO, D. S.; LOPES, M. C.; MESSAS, T. Gestão de Áreas Protegidas com Educação Ambiental Emancipatória pelo Ecoturismo Marinho: A proposta do Projeto Ecoturismar. OLAM - Ciencia e Tecnologia, Rio Claro (SP), n. 3, especial, pp. 6-81, 2011.

SECRETARIA DE MEIO AMBIENTE DE SÃO PAULO. Roteiros de Mergulho. Fundação Florestal, 200, 81p.

SENNA, M. L. G. S. de; ADORNO, L. F. M.; MAGALHÃES, H. G. D. Percepção ambiental e ecoturismo: estudo de caso com condutores de turismo e turistas na região do Jalapão/TO. OLAM Ciência e Tecnologia, Rio Claro (SP), v. 8, n. 2, pp. 218-244, jun. 2008. 
Percepção ambiental do mergulhador recreativo no Município do Rio de Janeiro e adjacências: subsídios para a sustentabilidade do ecoturismo marinho

SILVA, J. N.; GHILARDI-LOPES, N.P. Indicators of the impacts of tourism on hard-bottom benthic communities of Ilha do Cardoso State Park (Cananéia) and Sonho Beach (Itanhaém), two southern coastal áreas of São Paulo State (Brasil). Ocean and Coastal Management, v. 58, pp.1-8, 2012.

SILVA, I. B. ; FUJII, M. T.; MARINHO-SORIANO, E. Influence of tourist activity of seaweed from reefs in Maracajaú (Atlantic Ocean, Northeast Brazil). Revista Brasileira de Famacognosia, São Paulo, 2012 (no prelo).

TOWNSEND, C. The Effects of Environmental Education on the Behaviour of SCUBA Divers; A Case Study from British Virgin Island. 2000, $118 \mathrm{f}$. M.Sc. Thesis of Tourism, Conservation and Sustainable Development, University of Greenwich, Greenwich.

VASCONCELOS, F. A. L.; AMARAL, F. D.; STEINER, A. Q. Student's view of reef environments in the metropolitan area of Recife, Pernambuco state, Brazil. Arquivos de Ciências do Mar, Fortaleza, v. 4, n. 1, pp. 104-112. 2008.

WEDEKIN, L. Estudo de Capacidade de carga para Atividades de mergulho Educativo na Reserva Biológica Marinha do Arvoredo, Santa Catarina, Brasil. Relatório técnico não -publicado. Socioambiental Consultores Associados Ltda. Florianópolis, SC. 2003. 16 p.

ZAR, J.H. Biostatistical Analysis. $4^{\text {th }}$ ed. New Jersey: Prentice-Hall, 1999, 663 p.

Daniel Shimada Brotto: Universidade Veiga de Almeida, Rio de Janeiro, RJ, Brasil. Email: danshima@ig.com.br

Link para o currículo Lattes: http://lattes.cnpq.br/2411501175281264

Alexandre de Gusmão Pedrini: Universidade do Estado do Rio de Janeiro, Rio de Janeiro, RJ, Brasil.

Email: pedrini@globo.com

Link para o currículo Lattes: http://lattes.cnpq.br/6918956483557789

Raquel Ribeiro Cezar Bandeira: Universidade Veiga de Almeida, Rio de Janeiro, RJ, Brasil.

Email: raquelbandeira@hotmail.com

Link para o currículo Lattes: http://lattes.cnpq.br/8229892942105276

David Man Wai Zee: Universidade do Estado do Rio de Janeiro e Universidade Veiga de Almeida, Rio de Janeiro, RJ, Brasil.

Email: davidzee@uva.br

Link para o currículo Lattes: http://lattes.cnpq.br/2411501175281264

Data de submissão: 28 de fevereiro de 2012

Data de recebimento de correções: 13 de maio de 2012

Data do aceite: 22 de maio de 2012

Avaliado anonimamente 